\title{
ESTUDOS
}

\section{Uma análise comparativa da escrita de histórias pelos alunos de escolas públicas e particulares ${ }^{\star}$}

Maria Emília Lins e Silva

Alina Galvão Spinillo

Palavras-Chave: escrita de histórias; crianças; escola pública; escola particular.

* A Profa Maria Emília Lins e Silva agradece à Capes e à Facepe pelas bolsas conferidas para a realização do curso de mestrado, cuja dissertação, sob a orientação da Profa Alina Galvão Spinillo, deu origem a este artigo.

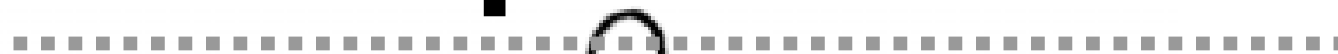


baseadas na Gramática de História. Observou-se uma progressão na habilidade narrativa das crianças após a alfabetização, e que os anos escolares freqüentados após a alfabetização contribuem para este desenvolvimento. Entretanto, os ganhos observados entre as crianças de classe média-alta foram mais expressivos do que entre as de baixa renda. Tal diferença foi interpretada em função de fatores sociolingüísticos quanto ao contato e interação que crianças de classes sociais distintas têm com a linguagem dos textos no ambiente familiar.

\section{A escrita de textos: aspectos envolvidos}

$O$ ato de escrever pressupõe um conjunto de aspectos que precisa ser considerado pelo escritor, tais como: o domínio do código alfabético, de regras ortográficas e gramaticais, pontuação, organização na exposição de idéias, aspectos intralingüísticos necessários, a distância entre escritor e leitor, etc.

Pontecorvo e Zucchermaglio (1989, p. 109) afirmam que "escrever requer um grande conjunto de opções lingüísticas e envolve uma linguagem mais elaborada e organizada (do que a fala)". Quando solicitado a escrever um texto, o escritor se depara com a necessidade de gerar idéias e de encontrar soluções lingüísticas de forma que o significado se encontre dentro do texto, expresso a partir de sua organização e elementos constituintes que o caracterizam, e com aspectos sintáticos da escrita.

Para Góes e Smolka (1992, p. 55), "escrever é um complexo jogo de estratégias onde o sujeito tem que coordenar o fluxo do pensamento, em que se relacionam o discurso interior e as formulações de enunciados comunicativos, com as operações quase sempre mais lentas do registrar".

De acordo com Rego (1988, p. 11), a produção escrita é "um produto lingüístico mais depurado" do que a linguagem oral, pois ao escrever, o sujeito tem a oportunidade de refletir sobre os aspectos formais da mensagem que deseja transmitir, fazer ajustes de forma que o produto escrito final não contenha lacunas, repetições desnecessárias e hesitações que estão geralmente presentes em uma produção oral.

Ao se considerar, em particular, a escrita de histórias, além dos aspectos mencionados, o narrador precisa lidar com as exigências textuais deste gênero, ou seja, o esquema narrativo, as convenções organizacionais e lingüísticas próprias deste gênero. Neste sentido, a escrita da história requer, ainda, dominar seus elementos constituintes, domínio este relacionado às habilidades narrativas do sujeito. Este aspecto é especificamente tratado no presente estudo.

\section{A escrita de textos: sua importância}

A importância do conhecimento do indivíduo sobre textos e de habilidades 
narrativas (seja quanto à produção, compreensão ou às habilidades metatextuais) é reconhecida por lingüistas, psicólogos e educadores. Recentemente, o reconhecimento desta importância tem se traduzido em propostas educacionais como aquelas apresentadas pelo MEC em seus Parâmetros Curriculares Nacionais relativos ao ensino de Língua Portuguesa. Neste documento, a importância do texto é explicitamente ressaltada em diversas passagens, bem como é igualmente mencionada a ineficácia da escola em desenvolver nos alunos habilidades textuais que permitam usar a linguagem escrita de forma ampla, extrapolando o domínio do código alfabético e das regras léxico-gramaticais. Nesta proposta, o texto assume lugar de destaque, inclusive o texto literário, e, em especial, a narrativa, como pode ser verificado na passagem a seguir:

Dentre as modalidades textuais da literatura, a narrativa tem importância fundamental durante todo o processo de aprendizagem. Além de ser o maior gênero da arte verbal - existiu nas culturas orais, consagrou-se na escrita e perdura nos meios audiovisuais - é o gênero que mais explorou a passagem da oralidade para o conhecimento letrado (p. 14).

Ao especificar os eixos organizadores básicos relativos ao desenvolvimento de habilidades lingüísticas, o documento insere a prática de produção de textos (seja oral ou escrita) como uma atividade de maior importância no processo de formação de usuários competentes da língua materna.

O trabalho com produção de texto tem como finalidade formar escritores competentes, capazes de produzir textos coerentes, coesos e eficazes. Para isto é necessária a aquisição de um conjunto de estratégias lingüísticas e cognitivas, fruto de uma prática continuada de produção dos mais variados textos (p. 2223) (destaque no original).

Considerando a importância e o status que a escrita de textos narrativos parece finalmente ter adquirido no currículo da educação fundamental, pesquisas sobre o tema tornam-se relevantes, principalmente aquelas que exploram aspectos psicolingüísticos da produção escrita de textos. A compreensão desses aspectos poderá contribuir para a implementação de práticas pedagógicas voltadas para o desenvolvimento de habilidades lingüísticas mais amplas, como as habilidades narrativas. Comparações entre crianças oriundas de camadas sociais distintas, como explorado neste estudo, adicionam, ainda, informações relevantes sobre a competência narrativa em crianças.

\section{Comparando crianças de classes sociais distintas}

Diferenças entre alunos de escolas públicas e particulares têm sido amplamente documentadas na literatura sobre competências lingüísticas (e.g., Carraher, 1986, 1989; Moreira, 1992; Albuquerque, Silva, Spinillo, 1996).

Moreira (1992), por exemplo, explorou as diferenças entre crianças de baixa renda e crianças de classe média, em relação às concepções sobre portadores de textos usualmente veiculados em uma sociedade letrada. Comparando em cada amostra crianças com diferentes níveis de escolaridade alfabetizadas ( $2^{\mathrm{a}}$ série) e não-alfabetizadas (pré-escolar) - , verificou que tanto as crianças pré-escolares como as da $2^{a}$ série da escola particular apresentavam níveis de compreensão acerca dos portadores de textos bem mais sofisticados do que as crianças de mesma série de baixa renda.

No entanto, ao comparar as mesmas séries nos dois tipos de escola, a autora não controlou os anos de escolaridade freqüentados pelas crianças. Este é um aspecto relevante, visto que a criança de baixa renda usualmente inicia a escolaridade aos 7 anos, freqüentando a $1^{\text {a }}$ série (série onde ocorre a alfabetização) que corresponde à sala de alfabetização na escola particular (crianças de 6 anos); enquanto a $1^{\text {a }}$ série das escolas particulares corresponde à $2^{a}$ série da escola pública (um ano após a alfabetização). Portanto, as séries não são equivalentes nem quanto ao conteúdo de que tratam, nem quanto aos anos escolares freqüentados pela criança ao ingressar no ensino fundamental.

A importância do fator anos de escolaridade em comparações desta natureza pode ser ilustrada quando se comparam os dados obtidos por Rego (1986) com crianças de $1^{\text {a }}$ série de escolas particulares, e por Buarque et al. (1992) com alunos da $1^{\text {a }}$ à $4^{\text {a }}$ série de escolas públicas. No estudo de Rego, observou-se que $47 \%$ das produções não eram consideradas histórias, enquanto no estudo de Buarque e cola- 
boradores, este índice era consideravelmente mais alto entre as crianças de mesma série de escola pública (85\%). À primeira vista, este resultado indica níveis de produção mais elementares entre crianças de baixa renda. Entretanto, quando se procede a um pareamento entre anos de escolaridade $\left(1^{\mathrm{a}}\right.$ série na particular versus $2^{\text {a }}$ série na pública), em vez de comparações diretas entre as séries nas duas classes sociais $\left(1^{a}\right.$ série na particular versus $1^{\text {a }}$ série na pública), observa-se que a diferença entre as duas escolas torna-se insignificante: $47 \%$ na 1 a série da escola particular e $48 \%$ na 2 a série da escola pública. Este exemplo demonstra a necessidade de nivelar grupos com um mesmo tempo de escolarização em vez de simplesmente comparar séries entre si, quando tais comparações envolvem os dois tipos de escola.

A pergunta que se coloca é, controlando os anos de escolaridade (i.e., de exposição formal à linguagem escrita no contexto escolar), quais as diferenças entre alunos dos dois tipos de escola quanto à produção escrita de histórias? Havendo diferenças, estas continuariam existindo com o passar do tempo (anos de escolaridade) ou os anos escolares tenderiam a nivelá-las?

\section{Método}

\section{Sujeitos}

Oitenta crianças, sendo 40 de classe média de escolas particulares (7-9 anos), e 40 crianças de baixa renda de escolas públicas (8-10 anos) da cidade do Recife. Os sujeitos, em cada escola, foram igualmente divididos em dois grupos, em função dos anos de escolaridade freqüentados após a alfabetização: um ano (1a série da escola particular e $2^{\underline{a}}$ série da escola pública) e três anos (3a série da escola particular e 4⿳a série da escola pública). Foram excluídos da amostra alunos com alguma repetência. Com este pareamento entre as séries, mantiveram-se constantes os anos de exposição ao ensino formal da língua escrita após a alfabetização em ambas as escolas.

\section{Procedimento e planejamento experimental}

Duas variáveis independentes foram consideradas neste estudo: os anos de

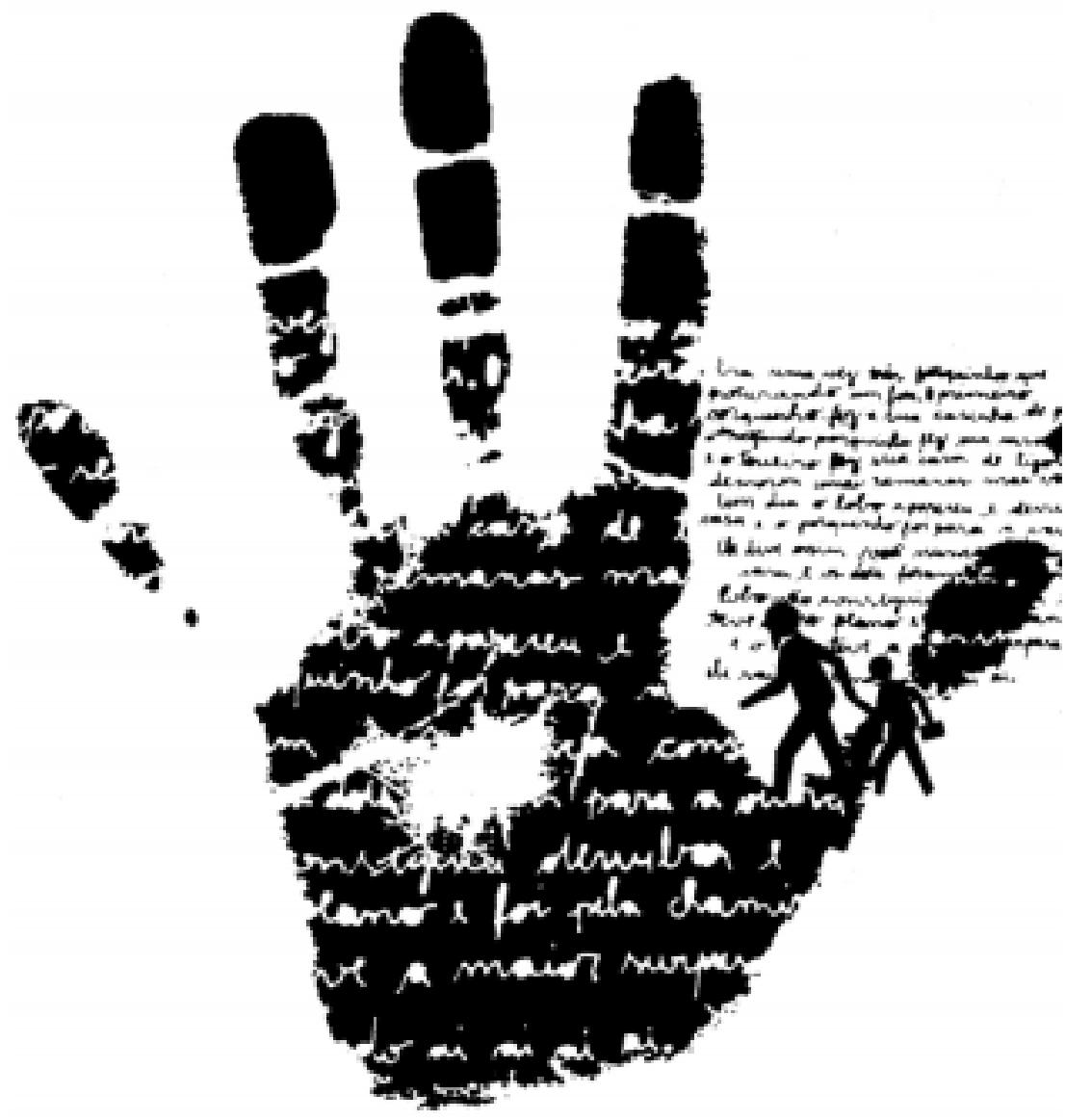

escolaridade (um ano e três anos) e o tipo de escola (particular e pública). $O$ tipo de escola, por sua vez, corresponde a duas classes sociais distintas: baixa renda (escola pública) e classe média alta (escola particular).

Utilizou-se, como controle, um teste de memória verbal que avalia a memória a curto prazo. Este instrumento tem sido amplamente adotado em estudos que investigam crianças, cujo desempenho em tarefas lingüísticas pode ser influenciado pela capacidade da memória a curto prazo. O teste consiste na apresentação de 12 sentenças, lidas uma por vez pelo experimentador. Após a leitura de cada sentença, a criança era solicitada a repetir a frase exatamente como a ouviu. A aplicação deste teste sempre antecedeu a produção escrita da história.

A situação experimental consistia na produção escrita, individual, de uma história original criada pelo sujeito. A aplicação foi coletiva, entregando-se aos sujeitos folhas de papel pautado, lápis e borracha. O tema, o tamanho da história e o tempo de duração para sua elaboração ficavam a critério do sujeito. 


\section{Análise das histórias}

As 80 histórias escritas foram classificadas em categorias, baseando-se na classificação de Rego (1986). Dois juízes independentes julgaram as produções, cujo índice de concordância foi de $85 \%$.

Categoria I - não-histórias, consistindo em frases soltas, seqüência de ações, relatos pessoais, texto cartilhado, músicas e poesias. Exemplo: ${ }^{1}$

O menino passeia de ônibus

O menino passeia de ônibus. Ele vê o gato, vê o avião, vê os carros e etc. Sabe pra onde ele está indo para a casa da vovó dele lá em Paulista. E para as casa das tias deles

Categoria II - introdução da cena e dos personagens, com a presença de marcadores lingüísticos convencionais de começo de história. Exemplo:

Era uma vez uma menina chamada Carla. ela gostava de brincar de boneca e também brincar de mãe e filha.

Categoria III - semelhante à categoria anterior, apresentando ainda uma ação que sugere o esboço de uma situação-problema. Exemplo:

Era uma vez uma boneca muito engraçada. Ela brincava, pulava, adorava as crianças. As crianças gostavam muito dela. Era a boneca mais cra do Brasil. Um dia Eles foram a praia foram com seus amigos. Um dia o pai de chego di vigem e quebrou a boneca. Ele não gostava da boneca.

Categoria $I V$ - semelhante à categoria anterior, apresentando também tentativa(s) de resolução da situação-problema, estando o desfecho ausente. Exemplo:

Era uma vez um lindo cachorinho que se perdeu na floresta e ele conheceu um garoto muito triste por que perdeu sua fanilha e estava perdido na mata com os animais que vivião com ele dorminha no chão sosinho com o cachoro um dia lindo como este estava dois homens casando quandu viro o garoto e pergundou 0 que ele estava fazendo ali sosinho na quele mato pegundou seu nome ele dise meo nome e Zesinho e meus pais morerão quando eu sai para pegar frutos dise zesinho quando eu estava vou tando escotei um barulho como se estivese espolindo eu cori para ver o que foi quando eu jegui estava peguando fogo dai eu vim paraca.

Categoria V-o desfecho, embora presente, não explicita como a situação-problema é resolvida. Exemplo:

O velhinho bondoso

Era uma vez um velhinho chamado

Joaquim.

Ele é muito bondoso.

Ele tinha 98 anos.

Um dia ele teve febre de $40^{\circ}$, ele ficou muito doente.

Depois de um dia ele já estava curado.

Ele morreu com 150 anos.

Categoria VI - histórias completas com uma estrutura narrativa elaborada, onde $o$ desfecho da trama é explicitado. Exemplo:

\section{UM MENINO TRISTE}

Era uma vez um menino muito triste. Quando ele ia para o colégio os amigos dele maltratava ele todo dia. até os amigos dele da rua. Um dia ele viu uma nave espacial caindo do céu. No outro dia ele foi ao local onde a nave caio. Quando ele vio era um extra rerrestre. Ele disse

- Você quer ser meu amigo. O menino disse

- Quero. Eu nunca tive um amigo. Então o extra terrestre disse

- Então nós dois somos amigos. O menino gritou oba. Então o menino ficou muito alegre.

\section{Resultados}

Os dados foram analisados através de uma análise descritiva multidimensional e de uma análise inferencial. A análise multidimensional $^{2}$ forneceu uma visão global da distribuição dos dados em função dos fatores que poderiam influenciar as produções escritas dos sujeitos: memória (índice obtido no teste de memória), anos de escolaridade e tipo de escola. Esta análise não indicou nenhum tipo de associação entre a memória e o desempenho dos sujeitos nesta tarefa, apontando apenas os anos de escolaridade como principal fator responsável pela distribuição e variação dos dados. A análise inferencial permitiu examinar em maiores detalhes as relações entre esses fatores através de testes estatísticos não-paramétricos. 
A Tabela 1 ilustra o desempenho dos alunos em função do tipo de escola.

\section{Tabela 1 - Porcentagem de histórias em cada categoria em função do tipo de escola}

\begin{tabular}{c|c|c} 
Categoria & Particular & Pública \\
\hline I & 25 & 20 \\
II & 15 & 25 \\
III & 7 & 10 \\
IV & 7 & 24 \\
V & 18 & 11 \\
VI & 27 & 10 \\
\hline
\end{tabular}

Fonte: Pesquisa de campo das autoras.

O Teste Kolmogorov-Smirnov apontou diferenças significativas entre as escolas $(p<.01)$. Mais crianças da escola pública (24\%) produzem histórias na Categoria IV (história incompleta, faltando o desfecho) do que crianças da escola particular (7\%); ocorrendo o oposto nas histórias da $\mathrm{Ca}$ tegoria $\mathrm{VI}$, visto que mais crianças da escola particular $(27 \%)$ produzem histórias nesta categoria (a mais elaborada) do que as crianças da escola pública (10\%). Esta diferença foi igualmente confirmada pelo Qui-quadrado $(p<.01)$.

Diferenças em função dos anos escolares encontram-se na Tabela 2.

O Teste U de Mann-Whitney foi aplicado sobre os dados relativos a cada escola separadamente, com o objetivo de se examinar o efeito dos anos de escolaridade sobre a história produzida. Em ambas as escolas, esta diferença foi significativa $(p<.05)$.

$\mathrm{Na}$ escola particular, as crianças com um ano de escolaridade concentram suas produções na Categoria I (35\%), que se caracterizam por textos que não são histórias. As crianças com três anos de escolaridade tendem a produzir histórias na Categoria VI (45\%), que se constituem histórias completas com um esquema narrativo elaborado. Além disso, enquanto apenas $10 \%$ das histórias produzidas ao final do primeiro ano escolar se incluem na Categoria VI, com três anos de escolaridade, este porcentual aumenta para $45 \%$. Isto indica claramente um efeito facilitador dos anos de escolaridade sobre a habilidade narrativa das crianças ao escreverem histórias.

$\mathrm{Na}$ escola pública, o efeito positivo dos anos escolares também é observado entre as crianças com um ano e com três anos de escolaridade. As histórias produzidas pelas primeiras se concentram na Categoria I (30\%), enquanto as produzidas pelas segundas se concentram na Categoria IV (35\%), que são histórias incompletas, porém com elementos estruturais e convenções lingüísticas próprias do gênero história.

Estes resultados indicam que, embora haja um efeito positivo dos anos escolares em ambas as escolas, este efeito parece ser menos marcante na escola pública do que na escola particular, como ilustrado na Tabela 3. As crianças com um ano de escolaridade não produzem histórias na Categoria VI (mais elaborada) e apenas $20 \%$ dessas histórias alcançam esta categoria após três anos de escolaridade.

Comparando-se as escolas, nota-se que após um ano de escolaridade 10\% das histórias da escola particular são classificadas na Categoria VI, enquanto nenhuma história produzida pelas crianças da escola pública se encontra nesta categoria. Após três anos de escolaridade, $45 \%$

Tabela 2 - Porcentagem de histórias por categoria, anos de escolaridade e escola

\begin{tabular}{|c|c|c|c|c|}
\hline & \multicolumn{2}{c|}{ Particular } & \multicolumn{2}{c|}{ Pública } \\
\hline Categoria & $\mathbf{1}$ ano & 3 anos & 1 ano & 3 anos \\
\hline I & 35 & 15 & 30 & 10 \\
II & 15 & 15 & 40 & 10 \\
III & 10 & 5 & 5 & 15 \\
IV & 5 & 10 & 10 & 35 \\
V & 25 & 10 & 15 & 10 \\
VI & 10 & 45 & 0 & 20 \\
\hline
\end{tabular}


das histórias escritas pelos alunos da escola particular alcançam a Categoria VI, enquanto na escola pública o porcentual é de apenas $20 \%$.

De modo geral, identifica-se uma evolução na competência narrativa em função dos anos de escolaridade em ambas as escolas. A diferença entre elas reside essencialmente no padrão de desenvolvimento de um esquema narrativo. Considerando os três anos de escolaridade, observa-se que as produções dos alunos da escola particular são mais elaboradas do que aquelas escritas pelos alunos da escola pública. Parece que esses três anos não são suficientes para garantir aos alunos da escola pública alcançar o mesmo nível de desempenho obtido pelas crianças da escola particular.

Para melhor discutir as diferenças quanto à aquisição de habilidades narrativas na produção escrita entre os dois períodos escolares investigados, elaborou-se a Tabela 3 , que apresenta de maneira mais resumida os dados obtidos neste estudo. Para tal, as freqüências de histórias escritas foram agrupadas da seguinte forma:

Não-História (NH), sendo incluídas todas as produções escritas que não se caracterizavam como histórias, correspondendo às produções da Categoria I.

Histórias Incompletas (HI), sendo incluídas as histórias incompletas, correspondendo às produções das Categorias II, III, IV e V.

Histórias Completas (HC), sendo incluídas as histórias escritas completas que correspondem às histórias escritas classificadas na Categoria VI.

Os porcentuais indicam que, para os alunos da escola particular, as diferenças entre um e três anos de escolaridade após a alfabetização se manifestam de duas maneiras: decresce de $55 \%$ para $40 \%$ o porcentual de histórias incompletas; e há um aumento de $10 \%$ para $45 \%$ na escrita de histórias completas.

Considerando as crianças da escola pública, verifica-se que após três anos de alfabetização o porcentual de histórias incompletas permanece o mesmo que aquele observado com um ano após a alfabetização (70\%). O ganho em habilidade narrativa, com o passar dos anos escolares, reflete-se apenas quanto ao fato de que após três anos, $20 \%$ das histórias são escritas de forma completa e elaborada, enquanto com um ano de escolaridade nenhuma das histórias escritas era completa.

Os anos de escolaridade influenciam o desenvolvimento de habilidades narrativas na escrita de histórias, mesmo após a alfabetização, pois mais crianças são capazes de escrever histórias completas ao final de três anos. Este desenvolvimento é mais acentuado entre os alunos de escola particular de classe média do que os da escola pública. As possíveis razões para esta diferença são discutidas a seguir.

\section{Discussão e conclusões}

Alguns aspectos são destacados nas discussões acerca dos resultados obtidos neste estudo: existe uma progressão na habilidade narrativa mesmo após a alfabetização, os anos de escolaridade que facilitam esta progressão, e observam-se diferenças entre os tipos de escola comparados.

A importância dos anos de escolaridade e 0 desenvolvimento de habilidades narrativas após a aquisição da leitura e da escrita

Os anos escolares após a alfabetização contribuem para o desenvolvimento de

Tabela 3 - Porcentagem de produções escritas completas (HC), incompletas (HI) e não-histórias ( $\mathrm{NH}$ ) em função dos anos de escolaridade em ambas as escolas

\begin{tabular}{lccccccc} 
& \multicolumn{3}{c}{ Particular } & \multicolumn{3}{c}{ Pública } \\
& NH & HI & HC & NH & HI & HC \\
$\mathbf{1}$ ano & 35 & 55 & 10 & 30 & 70 & 0 \\
$\mathbf{3}$ anos & 15 & 40 & 45 & 10 & 70 & 20 \\
\hline
\end{tabular}

Fonte: Pesquisa de campo das autoras. 
habilidades narrativas na escrita de histórias: crianças com três anos de escolaridade, após a alfabetização, escrevem histórias mais elaboradas do que crianças com um ano após a alfabetização. Assim, o conhecimento sobre como produzir histórias ainda está em desenvolvimento mesmo após o domínio da escrita, parecendo haver uma progressão, um caminho a ser percorrido para a aquisição de um esquema narrativo mais elaborado que não é garantido pela aquisição da leitura e da escrita. Isto indica que o domínio de um nível alfabético, das regras léxico-gramaticais $e$ de aspectos formais da escrita (pontuação, por exemplo) não geram automaticamente uma habilidade narrativa.

Este resultado pode ser melhor explorado em um estudo longitudinal, acompanhando-se as mesmas crianças durante um período de três anos, as quais poderiam ser avaliadas em diferentes momentos ao longo do período investigado.

A progressão observada se assemeIha àquela verificada na produção oral de histórias (Spinillo, Pinto, 1994), o que sugere que as categorias adotadas neste estudo são adequadas para analisar as produções escritas de histórias em crianças nas faixas etárias investigadas.

\section{A alfabetização não é suficiente para garantir 0 domínio de habilidades narrativas}

O fato de estar alfabetizado não garante a aquisição de habilidades narrativas mais elaboradas, pois muitas crianças já alfabetizadas não escreveram histórias completas e com uma estrutura elaborada. Uma possível explicação para esta fraca relação entre estar alfabetizado e ser um bom narrador é que, pelo menos nos moldes vigentes de práticas pedagógicas, predomina o ensino da língua enquanto código, centrando-se em unidades lingüísticas como a letra, a sílaba, a palavra e a frase. Em outras palavras, o processo de alfabetização tende a enfatizar o domínio de habilidades de codificação e decodificação. Um processo desta natureza se diferencia de uma abordagem da língua enquanto sistema de comunicação e de significados, onde unidades lingüísticas mais amplas, como o texto, por exemplo, são consideradas. Devido a isto, talvez se explique a fra- ca relação entre aquisição da leitura e da escrita e habilidades narrativas. Parece que habilidades narrativas se derivam de experiências com textos e não do domínio da leitura e da escrita de palavras e frases, sílabas e letras, da ortografia e da gramática. É evidente que tais conhecimentos são necessários; porém, são insuficientes para gerar habilidades narrativas que necessitariam de experiências com e sobre textos.

Uma possível evidência para a hipótese de que seria o contato com textos o principal fator determinante de habilidades narrativas textuais é o estudo recentemente desenvolvido por Nunes (1995). Nessa pesquisa, a autora examinou os ganhos lingüísticos derivados de duas práticas alfabetizadoras distintas: uma, que se caracterizava por uma ênfase no código como forma de acesso à leitura e à escrita; e outra, que se caracterizava por uma ênfase na língua como forma de comunicação. Dentre uma série de resultados extremamente relevantes, um resultado, em particular, interessa para a discussão ora desenvolvida: as crianças submetidas a uma prática cuja ênfase recaia sobre a língua apresentavam habilidades narrativas mais elaboradas quanto à escrita de histórias do que as crianças submetidas a outra prática alfabetizadora. É importante mencionar que a ênfase sobre a língua incluía uma prática voltada para atividades com textos diversos, em especial, a história. Assim, parece que não é o domínio do código e de suas convenções que geram as habilidades narrativas; mas, o contato e experiências com textos. Resultados como este foram também obtidos por Rego e Dubeux (1994) com crianças de escola pública submetidas a uma metodologia de ensino que incluía atividades sistemáticas com textos literários. A importância do contato com a linguagem dos textos para a aquisição de habilidades narrativas foi também ressaltada por Rego (1988) ao analisar a contribuição não apenas do ambiente escolar, mas também do ambiente familiar.

\section{As diferenças entre as crianças de escola pública e as de escola particular}

O presente estudo mostra que existem semelhanças e diferenças entre as crianças de baixa renda e de classe média
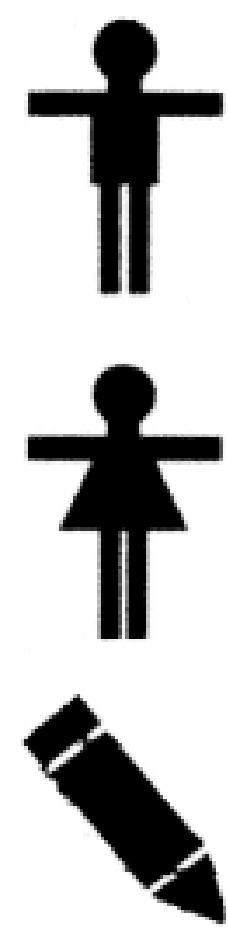

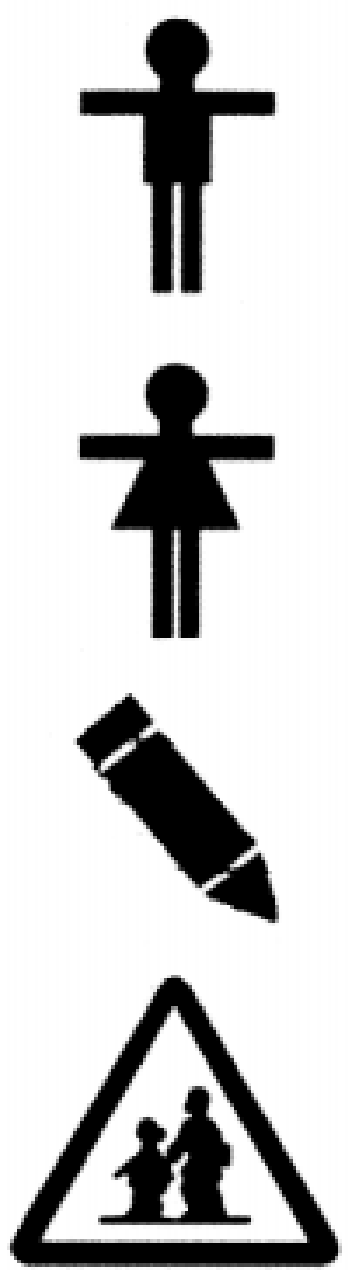

quanto à escrita de histórias. Para ambos os grupos, no início da escolaridade, escrever histórias completas com um esquema narrativo elaborado é tarefa difícil. A outra semelhança refere-se ao fato de que, decorridos três anos escolares, observa-se um maior domínio narrativo na escrita de histórias. As diferenças surgem no final desses três anos, quando os alunos da escola particular escrevem histórias mais elaboradas do que as crianças da escola pública. A escola, embora amplie as habilidades narrativas iniciais identificadas no primeiro ano após a alfabetização, não desenvolve na mesma extensão as habilidades narrativas das crianças das duas classes sociais. Como explicar, então, tais diferenças?

Uma primeira explicação possível é que as diferenças decorrem de práticas educacionais distintas quanto ao ensino da linguagem. Importante mencionar que as práticas educacionais de ambas as escolas se assemelhavam, quanto à forma como os textos (histórias em sua maioria) eram trabalhados em sala de aula. Observações desenvolvidas em salas de aula e de contatos feitos com as professoras mostraram que, em ambas as escolas, a produção escrita de histórias e o contato com os textos eram realizados ou com o objetivo de recreação ou como um meio para o ensino de ortografia, pontuação, gramática e ampliação de vocabulário. Nenhuma das escolas explorava o texto em função de suas características, organização e estrutura. Desta forma, parece que as diferenças não podem ser atribuídas a práticas pedagógicas distintas, uma vez que estas não se diferenciam efetivamente.

Uma segunda explicação é que tal resultado pode ser entendido como uma evidência a favor de uma teoria do déficit que atribui à criança de baixa renda um comprometimento de habilidades intelectuais. Esta explicação, entretanto, não encontra respaldo empírico, visto que pesquisas anteriores descartam esta interpretação (e.g., Carraher, Carraher, Schliemann, 1986, 1988; Carraher, 1989).

Uma terceira explicação é que os resultados podem ser interpretados em termos de fatores sociolingüísticos relativos a diferenças quanto às experiências, oportunidades, contatos e interações que crianças de classes sociais distintas vivenciam em relação à linguagem dos textos no ambiente familiar. Sem dúvida, o conhecimento sobre textos (como a história, por exemplo) possui origens em conhecimentos e usos derivados de interações em contextos sociais diversos. As crianças de classe média encontram no contexto familiar inúmeras oportunidades, contatos e experiências com a linguagem dos textos. O mesmo universo de experiências com a linguagem dos textos não ocorre com as crianças de baixa renda, como afirma Carraher (1986) e como verificou Moreira (1992). Assim, o contato com textos antes do ensino formal e fora do contexto escolar pode ser fator relevante na aquisição de formas mais elaboradas de escrita de histórias. Isto remete ao exame do contexto familiar de crianças de classe média e de baixa renda. De maneira geral, é sabido que nas famílias de baixa renda o nível de letramento é restrito, pouco se lê e pouco se escreve, o contato com textos narrativos praticamente não existe, não há livros de literatura infantil em casa, etc. Na realidade, para a criança de baixa renda, o contato mais efetivo com a língua escrita ocorre no contexto escolar. $A$ criança de classe média e alta, embora passando pelas mesmas restrições no contexto escolar, encontra no ambiente familiar oportunidades de contato com textos. A escola, entretanto, parece não considerar tais diferenças e, à medida que as ignora, as reforça, não contribuindo para a diminuição da desigualdade gerada pelas diferenças socioeconômicas.

O presente estudo demonstrou que tanto crianças de classe média como de baixa renda não dominam o estilo da linguagem dos textos nos primeiros anos escolares. As práticas pedagógicas, no entanto, parecem pressupor que este domínio já existe, ou não o privilegiam adequadamente. Em decorrência, esta postura contribui para o que Rego (1988, p. 77) denomina de analfabetismo funcional "que se manifesta em muitas crianças que, embora já alfabetizadas, apresentam sérias dificuldades na compreensão de textos escritos e revelam-se extremamente limitadas em termos de redação". Esta limitação, entretanto, parece ser superada pelas crianças de classe média, porém não pelas crianças de baixa renda.

O desenvolvimento da escrita de histórias parece não depender apenas dos anos escolares, mas de contatos efetivos com textos. Este contato precisa ser sistematicamente proporcionado pela escola, sobretudo por aquela que atende crianças de baixa renda, uma vez que o contexto 
familiar destas não propicia este tipo de desenvolvimento, sendo a escola o local onde este conhecimento é mais veiculado. As escolas públicas e as particulares deveriam tomar para si a responsabilidade de desenvolver habilidades lingüísticas mais amplas, como as habilidades narrativas. Quando a escola não garante este tipo de aprendizagem, as perdas são maiores para as crianças de baixa renda que têm no ambiente escolar a principal fonte de convívio com a linguagem dos textos. Este convívio, entretanto, deve ir além do uso de textos narrativos como pretexto para o ensino da ortografia, pontuação e regras gramaticais, ou do uso de textos como forma de recreação e lazer (como observado nas escolas deste estudo). Isto não significa afirmar que o uso de textos como instrumento para outras aquisições lingüísticas não deva ser feito, mas que o texto precisa ainda ser, ele próprio, objeto de reflexão e de aprendizagem. Um esforço neste sentido vem sendo feito em um estudo de intervenção com crianças de baixa renda em Recife, as quais são intensivamente expostas a situações que requerem analisar histórias quanto aos seus elementos constituintes, convenções e organização, comparando-se as habilidades narrativas dessas crianças antes e após a intervenção e com um grupo controle (Ferreira, em preparação).

\section{Referências bibliográficas}

ALBUQUERQUE, E. B. C., SILVA, M. E. Lins, SPINILLO, A. G. Para que serve ler e escrever? O depoimento de alunos e professores. Revista Brasileira de Estudos Pedagógicos, Brasília, v. 77, n. 187, p. 477-496, set./dez. 1996.

APPLEBEE, A. N. The child's concept of story. Chicago : University of Chicago Press, 1978.

BUARQUE L. L. et al. Avaliação do desempenho da rede pública escolar do Estado de Pernambuco na área de linguagem. Estudos em Avaliação Educacional, São Paulo, v. 5, jan./jun. 1992.

CARRAHER, T. N. Alfabetização e pobreza : três faces do problema. In: KRAMER, S. (Ed.). Alfabetização : dilemas da prática. Rio de Janeiro : Dois Pontos Editora, 1986. p. 47-97. . Sociedade e inteligência. São Paulo : Cortez, 1989.

CARRAHER, T. N., CARRAHER, D. W., SCHILIEMANN, A. D. Cultura, escola, ideologia e cognição : continuando um debate. Cadernos de Pesquisa, São Paulo, v. 57, p. 78-85, maio 1986.

. Na vida dez, na escola zero. São Paulo : Cortez, 1988.

FALCÃO, J. T. da R., REGNIER, J-C. Métodos quantitativos na pesquisa em psicologia : custo e benefício. (Em preparação).

FERREIRA, A. L. Produção e consciência metalingüística de textos em crianças : um estudo de intervenção. (Em preparação).

FRANCHI, E. E as crianças eram difíceis... : a redação na escola. São Paulo : Martins Fontes, 1984

GLENN, C. G. The role of episodic structure and of story length in children's recall of simple stories. Journal of Verbal Learning and Verbal Behavior, v. 17, p. 229-247, 1978. 
GÓES, M. C. R. de, SMOLKA, A. L. B. A criança e a linguagem escrita : considerações sobre a produção de textos. In: ALENCAR, E. S. (Org.). Novas contribuições da Psicologia aos processos de ensino e aprendizagem. São Paulo : Cortez, 1992. p. 51-70.

HUDSON, J. A., SHAPIRO, L. R. From knowing to telling : the development of children's scripts, stories, and personal narratives. In: McCABE, A., PETERSON, C. (Ed.). Developing Narrative Structure. Hillsdale : Lawrence Erlbaum Associates, 1991.

JOHNSON, N. S., MANDLER, J. M. A tale of two structures : underlying and surface forms in stories. Poetics, v. 9, p. 51-86, 1980.

KATO, M. No mundo da escrita : uma perspectiva psicolingüística. São Paulo : Ática, 1986.

KAUFMAN, A. M., RODRIGUEZ, M. E. Escola, leitura e produção de textos. Porto Alegre : Artes Médicas, 1995.

MANDLER, J. M., JOHNSON, N. S. Remembrance of things parsed : story structure and recall. Cognitive Psychology, v. 9, p. 111-151, 1977.

MATENCIO, M. de L. M. Leitura, produção de textos e escola. Campinas : Autores Associados, 1994.

MOREIRA, N. da C. R. Portadores de texto : concepções de crianças quanto a atributos, funções e conteúdo. In: KATO, M. A. (Org.). A concepção da escrita pela criança. Campinas : Pontes, 1992. p. 15-22.

NETO, A. G. A produção de textos na escola. São Paulo : Loyola, 1988.

NUNES, S. R. Comparando habilidades de leitura e escrita em crianças alfabetizadas por diferentes metodologias. Recife, 1995. Dissertação (Mestrado em Psicologia) Universidade Federal de Pernambuco.

OLIBERT, J. Formando crianças produtoras de texto. Porto Alegre : Artes Médicas, 1994.

PETERSON, C., McCABE, A. Developmental psycholinguistics : three ways of looking at child's narratives. New York : Plenum Press, 1983.

PONTECORVO, C., ZUCCHERMAGLIO, C. From oral to written language : preschool children dictating stories. Journal of Reading Behavior, v. 21, n. 2, p. 109-126, 1989.

REGO, L. L. B. A escrita de estórias por crianças : as implicações pedagógicas do uso de um registro lingüístico. Revista de Documentação de Estudos em Lingüística Teórica e Aplicada, v. 2, n. 2, p. 165-180, ago. 1986.

. Literatura infantil : uma nova perspectiva da alfabetização na pré-escola. São Paulo : FTD, 1988.

REGO, L. L. B., DUBEUX, M. H. Resultados de uma intervenção pedagógica no préescolar e no primeiro grau menor. In: BUARQUE, L. L., REGO, L. L. B. (Org.). Alfabetização e construtivismo : teoria e prática. Recife : Editora Universitária da UFPe, 1994. p. 66-78. (Série Estudos Universitários).

SILVA, M. A. S. S. Conquistando o mundo da escrita. São Paulo : Ática, 1994.

SOUZA, L. M. de, CARVALHO, S. W. de. Compreensão e produção de textos. Petrópolis : Vozes, 1995.

SPINILLO, A. G., PINTO, G. Children's narratives under different conditions : a comparative study. British Journal of Developmental Psychology, v. 12, p. 177-193, maio 1994. 
Recebido em 5 de março de 1998.

Maria Emília Lins e Silva, mestre em Psicologia pela Universidade Federal de Pernambuco (UFPe), é professora assistente do Centro de Educação dessa universidade.

Alina Galvão Spinillo, Ph.D. em Psicologia do Desenvolvimento pela Oxford University, Inglaterra, é professora adjunta do Departamento de Psicologia da Universidade Federal de Pernambuco (UFPe).

\section{Abstract}

The ability to write stories was compared in two different groups of children with different social backgrounds. All the children were literate, and in each group they varied according to the years of schooling they had attended. The written productions were analysed according to the domain of story scheme, based on Story Grammars. It was found that the ability to write stories develops even after the acquisition of written skills and that the years of schooling is an important factor in this progression. Differences were observed between the two groups: middle class children benefited more from the years of schooling than low class children whose written productions showed a low level of narrative structure. This difference was interpreted in terms of different social experiences with texts at home.

Key-Words: written stories; children; social class. 